\title{
An acido-triggered reversible luminescent and nonlinear optical switch based on a substituted styrylpyridine: EFISH measurements as an unusual method to reveal a protonation-deprotonation NLO contrast $\uparrow$
}

Cite this: Chem. Commun., 2014 50,1608

Received 24th October 2013, Accepted 3rd December 2013

DOI: $10.1039 / c 3 c c 48149 b$

www.rsc.org/chemcomm

\author{
Elena Cariati, ${ }^{a b c}$ Claudia Dragonetti, ${ }^{a b c}$ Elena Lucenti, ${ }^{\star b c}$ Filippo Nisic, ${ }^{a b}$ \\ Stefania Righetto, ${ }^{\mathrm{ab}}$ Dominique Roberto*abc and Elisa Tordin ${ }^{\mathrm{ab}}$
}

Diphenyl-(4-\{2-[4-(2-pyridin-4-yl-vinyl)-phenyl]-vinyl\}-phenyl)-amine (DPVPA) constitutes a novel acido-triggered reversible luminescent and nonlinear optical switch. Remarkably, for the first time the Electric-Field Induced Second Harmonic generation (EFISH) technique is used to reveal a protonation-deprotonation NLO contrast.

Compounds with second-order nonlinear optical (NLO) properties are important as molecular building block materials for optical communications, optical data processing and storage, or electrooptical devices. ${ }^{1}$ Among them, molecular species with commutable NLO properties are of growing interest. ${ }^{2}$ In fact, modulating the electronic and optical properties using an external trigger has been extended to the field of nonlinear optics and, in recent years, there has been significant interest in the ability to switch the second-order NLO response at the molecular level. The quadratic hyperpolarizability of chromophores may be manipulated by reversibly modifying the properties of specific parts of active molecules. The on-off switching may involve reducing the donor capacity of the electron-rich fragment of a typical donor-acceptor species, D-linkerA, by oxidation or protonation. Conversely, the acceptor behaviour of A can be altered by reduction, or by deprotonation. Alteration of the quadratic hyperpolarizability may also involve structural or chemical modification of the bridging group, thereby interfering with the communication between D and A. Thus, NLO switches can be achieved by a $\mathrm{pH}$ variation, by a redox process or by interaction with electromagnetic radiation. ${ }^{2}$

Of particular interest are organic acidochromes which display substantial NLO variations due to their ability to alternate between two distinct chemical forms having different absorption spectra in response to protonation-deprotonation.

The first studies on the NLO properties of acid-base couples were reported by Das, ${ }^{3}$ who elegantly obtained the dissociation constants

\footnotetext{
${ }^{a}$ Dipartimento di Chimica dell'Università degli Studi di Milano, via Golgi 19, 20133 Milano, Italy.E-mail: elena.cariati@unimi.it,dominique.roberto@unimi.it ${ }^{b}$ UdR INSTM di Milano, via Golgi 19, 20133 Milano, Italy

${ }^{c}$ ISTM-CNR, via Golgi 19, 20133 Milano, Italy.E-mail: e.lucenti@istm.cnr.it

$\dagger$ Electronic supplementary information (ESI) available. See DOI: 10.1039/c3cc48149b
}

of weak organic acids in solution by Hyper Rayleigh Scattering $(\mathrm{HRS})^{4}$ intensity measurements. Successively, different secondorder NLO contrasts have been studied by the HRS technique. For instance, a series of acidochromes based on benzimidazolo[2,3- $b$ oxazolidines, ${ }^{5}$ benzazolo-oxazolidines ${ }^{6}$ and indolino[2,1- $b$ ] ${ }_{\text {oxazo- }}$ lidine ${ }^{7}$ moieties show a remarkable contrast in the NLO response due to the reversible transformation of the oxazolidine closed form into a colored zwitterionic open form by acidification. Also, a series of push-pull molecules containing a 4,5-dicyanoimidazole acceptor (A) unit, an $N, N$-dimethylamino donor (D) group, and $\pi$-conjugated linkers $(\pi)$ were reported as pH-triggered NLO switches; protonation occurs at the $\mathrm{N}, \mathrm{N}$-dimethylamino function, which leads to disruption of the electronic charge-transfer delocalization: the A- $\pi-\mathrm{D}$ pattern of the neutral species with large quadratic hyperpolarizability $\beta$ values, as determined by HRS, was transformed into an $\mathrm{A}-\pi-\mathrm{A}^{\prime}$ pattern, which displayed much smaller $\beta$ values. $^{8}$

The high increase of the quadratic hyperpolarizability of variously substituted styryl pyridines upon coordination to a metal center ${ }^{9}$ or alkylation of the pyridine moiety ${ }^{10}$ prompted us to investigate the possibility of switching their second-order NLO response by the protonation-deprotonation reaction. In addition, since $\pi$-delocalized systems are often characterized by intense photoluminescence and in view of the recent and increasing interest in luminescent organic solids showing acidochromic switch of the emission, ${ }^{11}$ we also studied the transformation in solid state and in solution by emission spectroscopy. The molecular target chosen was the diphenyl-(4-\{2-[4-(2-pyridin-4-yl-vinyl)-phenyl]-vinyl\}-phenyl)-amine (DPVPA), a known luminescent $\pi$-delocalized chromophore, ${ }^{12,13}$ which second-order NLO properties had never been studied. In this communication, we present the results of this investigation that led to a new acido-triggered reversible luminescent and NLO switch. It is also shown for the first time that Electric-FieldInduced Second Harmonic generation (EFISH) measurements can be used as a convenient method to reveal a protonationdeprotonation NLO contrast.

DPVPA was easily prepared using a slightly modified version of the procedure reported in the literature (see Scheme 1). ${ }^{12,13}$ 


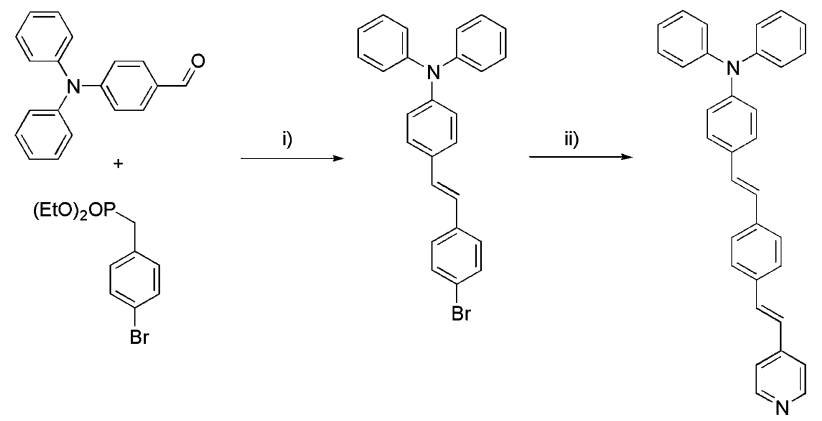

Scheme 1 Synthesis of diphenyl-(4-\{2-[4-(2-pyridin-4-yl-vinyl)-phenyl]vinyl\}-phenyl)-amine (DPVPA). (i) $t \mathrm{BuO}^{-} \mathrm{K}^{+}, \mathrm{THF}, \mathrm{RT}, 16 \mathrm{~h}, 85 \%$; (ii) vinylpyridine, bis(tri-tert-butylphosphine)palladium(0), toluene, $80{ }^{\circ} \mathrm{C}, 24 \mathrm{~h}, 90 \%$.

The UV-visible absorption spectrum of DPVPA in $\mathrm{CHCl}_{3}$ shows one major band at $410 \mathrm{~nm}$ which can be attributed to an intramolecular charge transfer transition (ICT) emanating from the $\mathrm{NPh}_{2}$ donor-end of the molecule. This absorption is red shifted with respect to that of dialkylamino styrylpyridine $\left(\lambda_{\max }\right.$ at $\left.381 \mathrm{~nm}\right)$, in agreement with a higher $\pi$-delocalisation. Upon exposure of a $\mathrm{CHCl}_{3}$ solution of DPVPA to $\mathrm{HCl}$ vapours for $1 \mathrm{~h}$, the absorption maximum is shifted to $485 \mathrm{~nm}$, a red-shift that can be attributed to protonation of the pyridine moiety with formation of [DPVPAH $]^{+} \mathrm{Cl}^{-}$, as confirmed by ${ }^{1} \mathrm{H}$ NMR spectroscopy (see Fig. 1 and ESI $\dagger$ ). The reverse transformation can be induced faster (about $30 \mathrm{~min}$ ) by treatment of the solution with $\mathrm{NH}_{3}$ vapours, as confirmed by ${ }^{1} \mathrm{H}$ NMR and absorption spectroscopy.

Interestingly, the protonation-deprotonation process is accompanied by a macroscopic variation in the emissive behaviour. In fact, DPVPA in $\mathrm{CHCl}_{3}$ displays an intense emission centred at $506 \mathrm{~nm}$ which is shifted to $665 \mathrm{~nm}$ upon exposure to $\mathrm{HCl}$ and restored after treatment with $\mathrm{NH}_{3}$ vapours. A similar, but much faster, interconversion process can be induced by exposure of powders or thin films of DPVPA dispersed in a polymethylmethacrylate (PMMA) matrix to $\mathrm{HCl}$ and ammonia vapours. The initial $558 \mathrm{~nm}$ emission of DPVPA powder is, in fact, shifted to $675 \mathrm{~nm}$ after less than 5 minutes of exposure to $\mathrm{HCl}$ vapours and restored by treatment with ammonia vapours (less than $5 \mathrm{~min}$ ). For PMMA thin films, the protonation is accomplished in less than 2 minutes, with

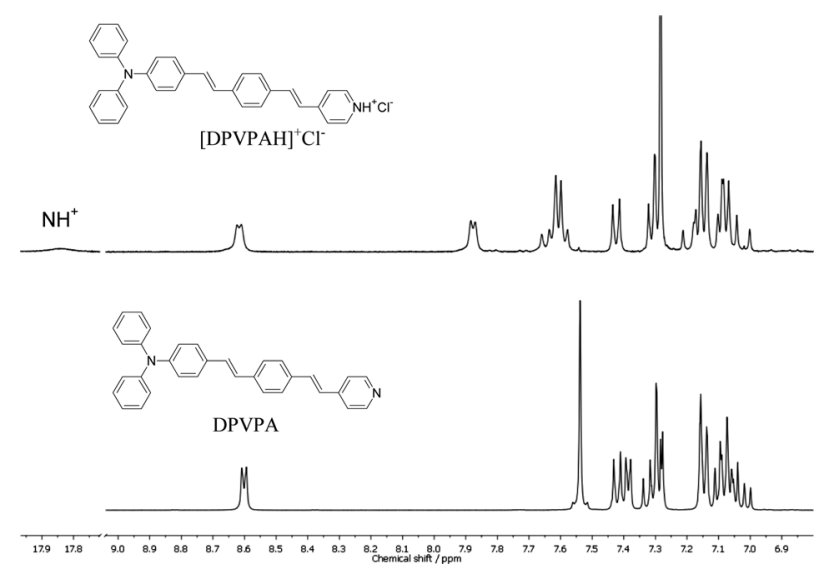

Fig. $1{ }^{1} \mathrm{H}$ NMR of DPVPA and [DPVPAH ${ }^{+} \mathrm{Cl}^{-}$in $\mathrm{CDCl}_{3}$ (inset: chemical structures of the two compounds).
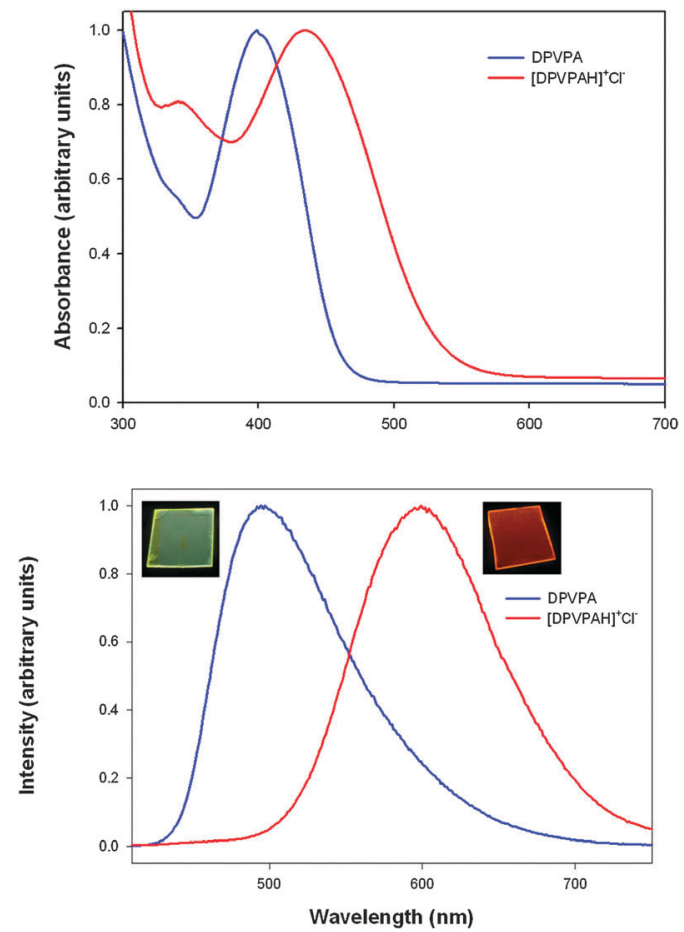

Fig. 2 Absorption (up) and emission (down) spectra of a DPVPA-PMMA thin film before (blue) and after (red) exposure to $\mathrm{HCl}$ vapours for $2 \mathrm{~min}$. A photograph of the protonated and unprotonated thin films under UV light is shown in the inset.

absorption maxima shifting from $399 \mathrm{~nm}$ (not protonated form) to $434 \mathrm{~nm}$ and emission maxima going from $497 \mathrm{~nm}$ to $599 \mathrm{~nm}$ (see Fig. 2). Even in this case, the reverse reaction is induced by exposure to ammonia vapours (less than $2 \mathrm{~min}$ ).

The observation of a $75 \mathrm{~nm}$ red-shift of the absorption band upon exposure of the $\mathrm{CHCl}_{3}$ solution to $\mathrm{HCl}$ vapours prompted us to monitor the second-order NLO properties during the DPVPA/ $[\text { DPVPAH }]^{+} \mathrm{Cl}^{-}$interconversion. In fact, the $[\mathrm{DPVPAH}]^{+} \mathrm{Cl}^{-}$low energy absorption band should be characterized by a significant increase in the dipole moment upon excitation from the ground to the excited state $\left(\Delta \mu_{\mathrm{eg}}\right)^{14}$ and therefore be responsible for a higher second-order NLO response of [DPVPAH $]^{+} \mathrm{Cl}^{-}$ with respect to DPVPA. ${ }^{15}$

Protonation-deprotonation NLO switches in solution are commonly studied by the HRS technique ${ }^{2}$ which, however, suffers the limitation of possible overestimation of the value of the quadratic hyperpolarizability due to multiphoton fluorescence. To our knowledge, the EFISH method ${ }^{16}$ has never been applied in such investigations, being usually considered offlimits for ionic species. However, it appears that the EFISH technique can be applied for the determination of the secondorder NLO response of ionic species by working in a solvent of a low dielectric constant such as $\mathrm{CHCl}_{3}$ which favours ionpairing. ${ }^{17}$ The observation of the easy interconversion between DPVPA and [DPVPAH $]^{+} \mathrm{Cl}^{-}$upon exposure of $\mathrm{CHCl}_{3}$ solutions to acid-base vapours prompted us to apply the EFISH method to study the NLO response of the DPVPA system upon protonationdeprotonation cycles. 


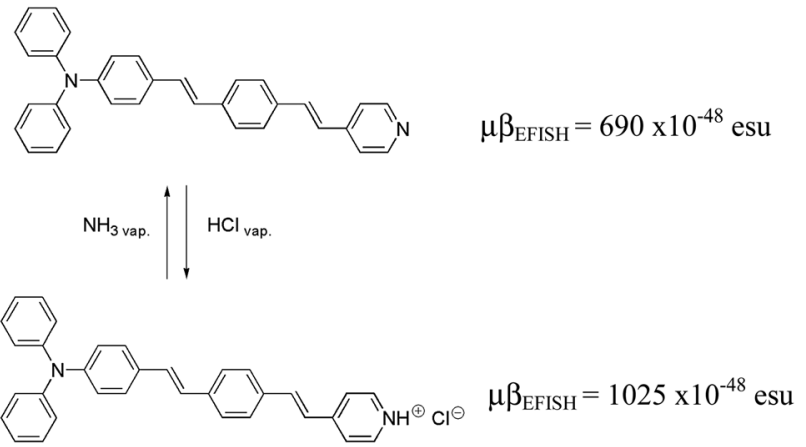

Scheme 2 An acido-triggered NLO switch based on DPVPA.

It is known that the EFISH technique ${ }^{16}$ can provide direct information on the intrinsic molecular NLO properties through eqn (1):

$$
\gamma_{\mathrm{EFISH}}=\left(\mu \beta_{\mathrm{EFISH}} / 5 k T\right)+\gamma(-2 \omega ; \omega, \omega, 0)
$$

where $\mu \beta_{\mathrm{EFISH}} / 5 k T$ is the dipolar orientational contribution to the molecular nonlinearity, and $\gamma(-2 \omega ; \omega, \omega, 0)$, the third order polarizability at frequency $\omega$ of the incident light, is a purely electronic cubic contribution to $\gamma_{\mathrm{EFISH}}$ which can usually be neglected when studying the second order NLO properties of dipolar compounds.

We found that DPVPA is characterized by a good value of $\mu \beta_{\text {EFISH }}\left(690 \times 10^{-48} \mathrm{esu}\right.$; the positive value of $\mu \beta_{\mathrm{EFISH}}$ is in agreement with an increase of the excited state dipole moment with respect to the ground state), working in $\mathrm{CHCl}_{3}$ at a concentration of $10^{-4} \mathrm{M}$ with a non-resonant incident wavelength of $1.907 \mu \mathrm{m}$, obtained by Raman-shifting the fundamental $1.064 \mu \mathrm{m}$ wavelength produced by a Q-switched, mode-locked $\mathrm{Nd}^{3+}$ :YAG laser.

The $\mu \beta_{\mathrm{EFISH}}$ of DPVPA increases by a factor of $1.5\left(\mu \beta_{\mathrm{EFISH}}=\right.$ $\left.1025 \times 10^{-48} \mathrm{esu}\right)$ upon protonation in the presence of $\mathrm{HCl}$ vapours, in agreement with the red shift of the absorption band, whereas further exposure to $\mathrm{NH}_{3}$ vapours restores (after filtration of the solution to remove $\mathrm{NH}_{4} \mathrm{Cl}$ which muddies the solution) the original value (Scheme 2).

In conclusion, DPVPA constitutes a new acido-triggered reversible luminescent and nonlinear optical switch. The alteration of the nonlinear properties is induced by the modulation of the internal charge-transfer due to the response of the molecule to protonation-deprotonation as the external stimulus. Remarkably, this communication unveils that the EFISH technique is a convenient and novel method to reveal a protonation-deprotonation NLO contrast. Moreover, based on the recent results reported by some of us on the application of the electric poling technique $^{18}$ for hybridizing thin films of ionic NLO chromophores, ${ }^{19}$ the use of this latter technique to detect acidochromic NLO contrasts for bulk materials can be envisaged. Studies on the reversible protonation of thin films of DPVPA dispersed in PMMA are currently under investigation in our laboratories.

This work was supported by MIUR (FIRB 2003: RBNE033KMA and FIRB 2004: RBPR05JH2P) and CNR.

\section{Notes and references}

1 J. Zyss, Molecular Nonlinear Optics: Materials, Physics and Devices, Academic Press, Boston, 1994.
2 (a) B. J. Coe, in Non-Linear Optical Properties of Matter, ed. M. G. Papadopoulos, A. J. Sadlej and J. Leszczynski, Springer Verlag, Berlin, 2006, 571; (b) V. Guerchais, L. Ordronneau and H. Le Bozec, Coord. Chem. Rev., 2010, 254, 2533; (c) K. A. Green, M. P. Cifuentes, M. Samoc and M. G. Humphrey, Coord. Chem. Rev., 2011, 255, 2530; (d) D. Marinotto, R. Castagna, S. Righetto, C. Dragonetti, A. Colombo, C. Bertarelli, M. Garbugli and G. Guglielmo, J. Phys. Chem. C, 2011, 115, 20425; (e) F. Castet, V. Rodriguez, J. L. Pozzo, L. Ducasse, A. Plaquet and B. Champagne, Acc. Chem. Res., 2013, 46, 2656.

3 (a) P. C. Ray and P. K. Das, J. Phys. Chem, 1995, 99, 17891; (b) P. K. Das, J. Phys. Chem. B, 2006, 110, 7621.

4 (a) P. D. Maker, Phys. Rev. A, 1970, 1, 923; (b) J. Zyss, J. Chem. Phys., 1993, 98, 6583; (c) K. Clays and A. Persoons, Phys. Rev. Lett., 1991, 66, 2980; (d) J. Zyss and I. Ledoux, Chem. Rev., 1994, 94, 77.

5 L. Sanguinet, J.-L. Pozzo, M. Guillaume, B. Champagne, F. Castet, L. Ducasse and E. Maury, J. Phys. Chem. B, 2006, 110, 10672.

6 F. Mançois, L. Sanguinet, J.-L. Pozzo, M. Guillaume, B. Champagne, V. Rodriguez, F. Adamietz, L. Ducasse and F. Castet, J. Phys. Chem. B, 2007, 111, 9795.

7 F. Mançois, J.-L. Pozzo, J. Pan, F. Adamietz, V. Rodriguez, L. Ducasse, F. Castet, A. Plaquet and B. Champagne, Chem.-Eur. J., 2009, 15, 2560.

8 A. Plaquet, B. Champagne, J. Kulhánek, F. Bureš, E. Bogdan, F. Castet, L. Ducasse and V. Rodriguez, ChemPhysChem, 2011, 12, 3245.

9 (a) S. Di Bella, C. Dragonetti, M. Pizzotti, D. Roberto, F. Tessore and R. Ugo, Top. Organmet. Chem., 2010, 28, 1; (b) O. Maury and H. Le Bozec, in Molecular Materials, ed. D. W. Bruce, D. O'Hare and R. I. Walton, Wiley, Chichester, 2010, pp. 1-59.

10 D. Locatelli, S. Quici, S. Righetto, D. Roberto, F. Tessore, G. J. Ashwell and M. Amiri, Prog. Solid State Chem., 2005, 33, 223.

11 D. Liu, Z. Zhang, H. Zhang and Y. Wang, Chem. Commun., 2013, 49, 10001.

12 Y.-X. Yan, X.-T. Tao, Y.-H. Sun, C.-K. Wang, G.-B. Xu, J.-X. Yang, Y. Ren, X. Zhao, Y.-Z. Wu, X.-Q. Yu and M.-H. Jiang, J. Mater. Chem., 2004, 14, 2995.

13 Y.-X. Yan, X.-T. Tao, Y.-H. Sun, W.-T. Yu, G.-B. Xu, C.-K. Wang, H.-P. Zhao, J.-X. Yang, X.-Q. Yu, X. Zhao and M.-H. Jiang, Bull. Chem. Soc. Jpn., 2005, 78, 300.

14 (a) B. J. Coe, J. A. Harris, I. Asselberghs, K. Clays, G. Olbrechts, A. Persoons, J. T. Hupp, R. C. Johnson, S. J. Coles, M. B. Hursthouse and K. Nakatani, Adv. Funct. Mater., 2002, 12, 110; (b) B. J. Coe, J. A. Harris, I. Asselberghs, K. Wostyn, K. Clays, A. Persoons, B. S. Brunschwig, S. J. Coles, T. Gelbrich, M. E. Light, M. B. Hursthouse and K. Nakatani, Adv. Funct. Mater., 2003, 13, 347.

15 An increase of the hyperpolarizability can be observed both with an increase of the excited state dipole with respect to the ground state one, leading to a positive $\Delta \mu_{\mathrm{eg}}$, and with a decrease of the excited state dipole with respect to the ground state one, leading to a negative $\Delta \mu_{\mathrm{eg}}$.

16 (a) B. F. Levine and C. G. Bethea, J. Chem. Phys., 1975, 63, 2666; (b) I. Ledoux and J. Zyss, Chem. Phys., 1982, 73, 203.

17 (a) V. Alain, M. Blanchard-Desce, I. Ledoux-Rak and J. Zyss, Chem. Commun., 2000, 353; (b) A. Valore, E. Cariati, C. Dragonetti, S. Righetto, D. Roberto, R. Ugo, F. De Angelis, S. Fantacci, S. Sgamellotti, A. Macchioni and D. Zuccaccia, Chem.-Eur. J, 2010, 16, 4814; (c) F. Tessore, E. Cariati, F. Cariati, D. Roberto, R. Ugo, P. Mussini, C. Zuccaccia and A. Macchioni, ChemPhysChem, 2010, 11, 495; (d) D. Roberto, A. Colombo, D. Locatelli, F. Tessore, R. Ugo, M. Cavazzini, S. Quici, F. De Angelis, S. Fantacci, I. Ledoux-Rak, N. Tancrez and J. Zyss, Dalton Trans., 2012, 41, 6707.

18 (a) D. Marinotto, S. Proutière, C. Dragonetti, A. Colombo, P. Ferruti, D. Pedron, M. C. Ubaldi and S. Pietralunga, J. Non-Cryst. Solids, 2011, 357, 2075; (b) D. Roberto, A. Colombo, C. Dragonetti, D. Marinotto, S. Righetto, S. Tavazzi, M. Escadeillas, V. Guerchais, H. Le Bozec, A. Boucekkine and C. Latouche, Organometallics, 2013, 32, 3890; (c) C. Dragonetti, A. Colombo, D. Marinotto, S. Righetto, D. Roberto, A. Valore, M. Escadeillas, V. Guerchais, H. Le Bozec, A. Boucekkine and C. Latouche, J. Organomet. Chem., 2013, DOI: 10.1016/ j.jorganchem.2013.09.003.

19 (a) R. Macchi, E. Cariati, D. Marinotto, E. Tordin, R. Ugo, G. Santoro, M. C. Ubaldi, S. M. Pietralunga and G. Mattei, J. Mater. Chem., 2011, 21, 9778; (b) R. Macchi, E. Cariati, D. Marinotto, D. Roberto, E. Tordin, R. Ugo, R. Bozio, M. Cozzuol, D. Pedron and G. Mattei, J. Mater. Chem., 2010, 20, 1885. 